\title{
The EARly IMPACT OF THE INDIANA SCHEdULed PRESCRIPTION ELECTRONIC Collection and Tracking ("INSPECT") Program: A Potentially Effective Policy Tool for Reducing Prescription Drug Abuse
}

Eric R. Wright, Ph.D., ${ }^{*}$ Harold E. Kooreman, MA, MSW,** Marion S. Greene, MPH, Ph.D.***

* An early version of this invited paper was presented as part of the panel presentation, "Prescription Drug Policy: A Case Study in Public Health Law and Policy" for the Indiana Health Law Review Symposium, Indianapolis, Indiana, October 19, 2015. The authors acknowledge the funding provided by the Indiana Professional Licensing Agency through grant \#A262-3-250-107 awarded by U.S. Department of Justice, Office of Justice Programs, and the Harold Rogers Prescription Drug Monitoring Program. The authors wish to thank Marty Allain, Holly Walpole, Greg Pachmayr, and Taya Fernandez and the current and former staff of the Indiana Professional Licensing Agency for their technical assistance with accessing the INSPECT data over the past several years.

\section{TABLE OF CONTENTS}

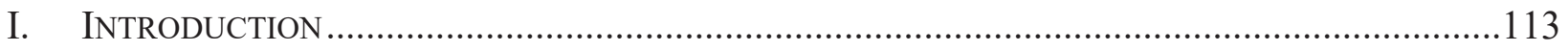

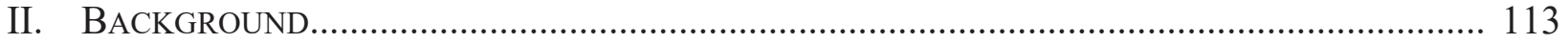

A. INSPECT - Indiana's PDMP

III. Key Findings From Analysis of INSPECT System Data.

A. Trends in Opioid Dispensations

B. Doctor-Shopping

IV. Key Findings from the 2013 Survey of Prescribers' and DisPenSERs' Use of INSPECT
A. Factors Associated with INSPECT Use
B. Frequency of INSPECT Use
C. Change in Prescribing Practices in the Past Twelve Months

V. CONCLuSION .127

* Eric R. Wright, Ph.D., Chair, Department of Sociology 2nd Century Initiative Professor of Sociology and Public Health Georgia State University

**Harold E. Kooreman, MA, MSW, Policy Analyst, Center for Health Policy Richard M. Fairbanks School of Public Health Indiana University Purdue University Indianapolis;

***Marion S. Greene, MPH, PhD(c), Public Health Research Analyst, Center for Health Policy Richard M. Fairbanks School of Public Health Indiana University Purdue University Indianapolis. 


\section{ABSTRACT}

Over the past decade, prescription drug misuse and abuse has emerged as a significant and growing public health problem in the United States. Federal and state officials have advocated for and created state-based prescription drug monitoring programs ("PDMPs") as a policy tool to help public health and law enforcement officials address this emerging epidemic. In this paper, we provide an overview of Indiana's PDMP, known as the Indiana Scheduled Prescription Electronic Collection and Tracking ("INSPECT") Program, and summarize key findings from analyses of the early impact of the implementation of the program in Indiana. Overall, the evaluation suggests that INSPECT is having an impact both in reversing the aggregate supply of prescription drugs, especially opioids, and changing the attitudes as well as the prescribing and dispensing behavior of providers across the Hoosier state.

\section{INTRODUCTION}

Over the last two decades, the level of non-medical use ${ }^{1}$ and diversion of controlled prescription medication in the United States has risen to epidemic proportions. ${ }^{2}$ The U.S. Office of National Drug Control Policy, the Centers for Disease Control ("CDC"), and other federal and state policy agencies and advocacy groups have strongly supported the use of state-run Prescription Drug Monitoring Programs ("PDMPs") as potentially effective tools for reducing the nonmedical use of prescription opioid. ${ }^{3}$ While federal and state officials are investing heavily in PDMPs, scientific and policy understanding of the effectiveness of these efforts is still developing.

This paper provides an overview of Indiana's PDMP and key findings from an evaluation of the program's early impact on accessibility of prescription drugs at the population-level and prescriber and dispenser practice patterns.

\section{BACKGROUND}

In 2014, the National Survey on Drug Use and Health ("NSDUH") estimated that over 54 million Americans (20.5\%) ages twelve years and older had used prescription-type psychotherapeutics non-medically at some point during their lifetime, with 6.5 million $(2.5 \%)$

${ }^{1}$ Non-medical use refers to use of a controlled prescription medication, "whether obtained by prescription or otherwise, other than in the manner or for the reasons or time period prescribed, or by a person for whom the drug was not prescribed." UNITED NATIONS OFFICE ON DRUGS \& CRIME, The Non-Medical Use of Prescription Drugs: Policy Direction Issues 1 (2011), https://www.unodc.org/ [https://perma.cc/BM8R-E44V].

${ }^{2}$ Ctrs. for Disease Control \& Prevention, Vital Signs: Overdoses of Prescription Opioid Pain Relievers-United States, 1999-2008, 60 Morbidity \& Mortality WkLY. ReP. 1487, 1489 (November 4, 2011) [hereinafter Vital Signs: United States 1999-2008]; see also S. H. Hernandez \& L. S. Nelson, Prescription Drug Abuse: Insight Into the Epidemic, 88 ClinICAL PHARMACOLOGY \& THERAPEUTICS 307, 307 (2010).

3 Jessica M. Irvine et al., Who Uses a Prescription Drug Monitoring Program and How? Insights from a Statewide Survey of Oregon Clinicians, 15 J. OF PAIN 747, 747 (2014). 
reporting to be current users. ${ }^{4}$ While central nervous system depressants (e.g., Alprazolam, Phenobarbital) and central nervous system stimulants (e.g., Methylphenidate, Lisdexamfetamine) are frequently used for non-medical purposes, the most widely misused and abused class of controlled prescription medication is opioid analgesics (e.g., Hydrocodone, Oxycodone), with 4.3 million Americans currently engaging in nonmedical use. ${ }^{5}$

Curbing non-medical use of opioid pain medication is critical. During 2006, non-medical use of prescription opioids cost the United States $\$ 53.4$ billion in lost productivity, criminal justice activity, drug abuse treatment, and medical complications. ${ }^{6}$ Non-medical use of opioid analgesics has resulted in over 165,000 overdose deaths since 1999, with at least 14,000 of those deaths occurring in $2014 .^{7}$

Data suggest that the high rate of non-medical use of opioid analgesics in the United States is being driven by the high rate at which these drugs are prescribed. ${ }^{8}$ The CDC reported that, in 2012, healthcare providers wrote 259 million prescriptions for opioid pain medications, ${ }^{9}$ enough for every U.S. citizen to take a $5 \mathrm{mg}$ dose of hydrocodone every four hours a day for one month. ${ }^{10}$ Although most people who misuse opioid analgesics get them from friends and family, ${ }^{11}$ physicians still play a role in the epidemic by providing prescriptions to patients in their practice

${ }^{4}$ Substance Abuse \& Mental Health Servis. Admin., Behavioral Health Trends in The U.S.: Results FROM the 2014 NAtional Survey on Drug Use AND Health 6 (2014), http://www.samhsa.gov/ [https://perma.cc/M2BN-HMVG].

${ }^{5}$ Id. at 1, 5, 7; William M. Compton \& Nora D. Volkow, Abuse of Prescription Drugs and the Risk of Addiction, Drug AND Alcohol DePEndence 83, S4-S7 (2006).

${ }^{6}$ Ryan N. Hansen et al., Economic Costs of Nonmedical Use of Prescription Opioids, 27 CliniCAL J. PAIN 194, 198 (2011).

7 Prescription Opioid Overdose Data, Ctrs. FOR Disease Control \& Prevention, http://www.cdc.gov/ [https://perma.cc/HWC5-G27G] (last updated June 21, 2016).

${ }^{8}$ See Wilson M. Compton \& Nora D. Volkow, Major Increases in Opioid Analgesic Abuse in the United States: Concerns and Strategies, 81 DRUG \& Alcohol DePENDENCE 103, 103-07 (2006); see also Robert J. Fortuna et al., Prescribing of Controlled Medications to Adolescents and Young Adults in the United States, 126 PEDIATRICs 1108, 1108-16 (2010); see also Bridget M. Kuehn, Opioid Prescriptions Soar: Increase in legitimate Use As Well As Abuse, 297 JAMA 249, 249-51 (2007); see also Laxmaiah Manchikanti \& Angelie Singh, Therapeutic Opioids: A Ten-Year Perspective on the Complexities and Complications of the Escalating Use, Abuse, and Nonmedical Use of Opioids, 11 Pain Physician (SPECIAL Issue) S63, S63-88 (2008); see also Jane Carlisle Maxwell, The Prescription Drug Epidemic in the United States: The Perfect Storm, 30 DRUG \& REVIEW 264, 264-270 (2011).

${ }^{9}$ Ctrs. for Disease Control \& Prevention, Opioid Painkiller Prescribing: Where You Live Makes a Difference 1, CDC VITAL SignS (July 2014), http://www.cdc.gov/ [https://perma.cc/S66D-7FPV].

${ }^{10}$ Vital Signs: United States 1999-2008, supra note 2.

11 Opioids, Substance Abuse and Mental Health Servs. Admin. ("SAMHSA"), http://www.samhsa.gov/atod/opioids [https://perma.cc/6XWC-GLWM] (last updated Feb. 23, 2016); see generally THE CENTER FOR BEHAVIORAL HEALTH STATISTICS AND Quality

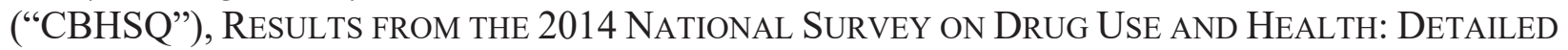
TABLES (Melissa H. Hargraves et al. eds., (2015). 
who are doctor shopping and pharmacy shopping. ${ }^{12}$ Doctor shopping is the practice of consulting several physicians in order to receive multiple simultaneous prescriptions for a specific drug of abuse, ${ }^{13}$ while pharmacy shopping refers to the use of multiple pharmacies to simultaneously fill the multiple prescriptions. ${ }^{14}$ Controlling doctor shopping and pharmacy shopping is important as data suggest that some individuals who experience fatal overdoses from opioid analgesics often received their medications through these practices. ${ }^{15}$

Several federal agencies, including the Office of National Drug Control Policy and the CDC, have strongly supported the use of PDMPs as an effective method for reducing doctor and pharmacy shopping and also in decreasing the non-medical use of prescription opioids and its related consequences. ${ }^{16}$ PDMPs are state-level, electronic databases collecting information on the dispensation of controlled substances. ${ }^{17}$ The data contained within PDMPs can be used to support clinical decision-making and justify medical use of controlled substances; identify or prevent drug abuse and diversion; help identify persons possibly addicted to prescription medication and allow for intervention and treatment; highlight trends in drug use and misuse to inform public health initiatives; or educate healthcare professionals and the public about prescription drug use, abuse, diversion and PDMPs. ${ }^{18}$ As of 2014, forty-nine states and one U.S. territory have functioning PDMPs, while the District of Columbia has enacted legislation authorizing the development and operation of a PDMP. ${ }^{19}$

12 Douglas C. McDonald \& Kenneth E. Carlson, Estimating the Prevalence of Opioid Diversion by “Doctor Shoppers" in the United States, PLOS ONE 1, July 2013.

13 Thomas Clark et Al., Prescription Drug Monitoring Programs: An Assessment of The Evidence for Best Practices 3-4 (The Prescription Drug Monitoring Program Center of Excellence, Sept. 20, 2012), http://www.pewtrusts.org [https://perma.cc/7A2C-8ZUX].

${ }^{14}$ See, e.g., H. Buurma, et al., Prevalence and Determinants of Pharmacy Shopping Behaviour. 33 J. Clinical Pharmacy \& Therapeutics 17, 17-23. (2008).

${ }^{15}$ Leonard J. Paulozzi et al., A History of Being Prescribed Controlled Substances and Risk of Drug Overdose Death, 13 PAIN MED. 87, 87-95 (2012); Gretchen L. Peirce et al., Doctor and Pharmacy Shopping for Controlled Substances, 50 MED. CARE 494, 494-500 (2012); Grentchen P. Smith, et al., Doctor and Pharmacy Shopping for Controlled Substances, 50 MediCAL CARE 494, 494-500 (2012).

${ }^{16}$ Irvine et al., supra note 3.

${ }^{17}$ Kristen Finklea et. al., Prescription Drug Monitoring Programs, 10 J. Drug Addiction, EDUC., \& ERADICATION 481, 481-505 (2014).

18 Id.; see also PDMP TTAC, FAQS, PDMPASSIST.ORG, http://www.pdmpassist.org [https://perma.cc/ZJU7-FQAC] (last visited Jan. 10, 2017) [hereinafter PDMP FAQS].

${ }^{19}$ PDMP FAQs, supra note 18. 


\section{A. INSPECT - Indiana's PDMP}

In the mid-1990s, the Indiana General Assembly passed legislation to start a PDMP that would come to be known as the INSPECT Program. ${ }^{20}$ In its initial form, the program required Indiana's licensed pharmacies to only report Schedule II controlled substance sales into the Central Repository for Controlled Substances Data. Starting in 2004, reporting requirements for INSPECT were expanded. Licensed pharmacies are now required to report on all Schedule II through V controlled substances dispensed on an outpatient basis. ${ }^{21}$ Licensed pharmacies are all in-state and out-of-state pharmacies that can legally dispense drugs in Indiana. ${ }^{22}$ INSPECT is funded partly by the Harold Rogers grant program and partly by state-level funds acquired from a percentage of controlled substance licensing fees. ${ }^{23}$

Data for INSPECT are collected each time a controlled substance is dispensed, and the dispenser is required to submit the following information: the recipient's name, identification number, and date of birth; the national drug code number of the controlled substance dispensed, the date of dispensation, the quantity of the controlled substance dispensed, the number of days of supply dispensed, whether the prescription was transmitted to the dispenser orally or in writing, the recipient's method of payment for the controlled substance dispensed, the dispenser's U. S. Drug Enforcement Agency registration number, the prescriber's U. S. Drug Enforcement Agency registration number, and the patient's address information including city, state, and zip code. ${ }^{24}$

INSPECT's primary function is to help address the problem of prescription drug abuse and diversion in the State by maintaining a warehouse of patient information for healthcare professionals and also serving as an important investigative tool for law enforcement. ${ }^{25}$ To meet these goals, Indiana law grants access to INSPECT data to any certified practitioner, for the purpose of actively and directly "providing medical or pharmaceutical treatment; or evaluating the need for providing" such treatment to a patient. ${ }^{26}$ Practitioners are defined as any "physician, dentist, veterinarian, podiatrist, nurse practitioner, scientific investigator, pharmacist, hospital or other institution or individual licensed, registered, or otherwise permitted to distribute, dispense, conduct research with respect to, or administer a controlled substance in the course of professional practice or research in the United States." 27

Other groups who can access INSPECT data are licensing boards, the Indiana Attorney General's Office, and law enforcement agencies when they are involved in conducting investigations related to abuse and/or diversion of controlled substances that fall under schedules II, III, IV, and $\mathrm{V}^{28}$ In order to provide practitioners with the most complete data possible about their patients, the Indiana Professional Licensing Agency ("IPLA") has worked to develop data

20 Indiana Professional Licensing Agency, About INSPECT, IN.Gov, http://www.in.gov/ [https://perma.cc/MEE3-56ED] (last visited Nov. 10, 2016) [hereinafter About INSPECT].

${ }^{21}$ Id.

${ }^{22} \mathrm{Id}$.

${ }^{23} I d$.

${ }^{24}$ FAQS, supra note 22.

${ }^{25}$ About INSPECT, supra note 20.

${ }^{26}$ Ind. Code $\S 35-48-7-11.1$ (d)(4), (e)(1)-(2) (2016).

${ }^{27}$ Id. $\S 35-48-7-5.8$.

${ }^{28}$ Id. $\S 35-48-7-11.1(\mathrm{~d})(1)-(3)$. 
sharing agreements with neighboring states that allow Indiana practitioners direct access to PDMP data from four neighboring and 17 non-neighboring states. ${ }^{29}$

Senate Enrolled Act No. 246 ("SEA 246”) required Indiana's Medical Licensing Board to adopt an Emergency Rule for establishing standards and protocols for chronic pain management. The Emergency Rule was adopted in 2013 and final regulations were developed by November 2014 (844 Indiana Administrative Code 5-6). These regulations require physicians to check the database before starting a patient with nonterminal chronic pain on an opioid treatment plan, and at least annually thereafter, as well as document in the patient's chart if the INSPECT findings are consistent with their knowledge of the patient's history of controlled substance use. As of January 2016, pharmacies must upload all controlled substance dispensations to INSPECT within 24-hours of dispensation to allow healthcare providers real-time access to prescription histories. ${ }^{30}$ To assess the early impact of INSPECT, we analyzed the current INSPECT data as well as data from a 2013 survey of end users, i.e., prescribers and dispensers across Indiana. In the following sections, we summarize findings from these analyses, which focus primarily on calendar year 2014. The information presented in this paper build on and extend prior reports from our multi-year evaluation, which are publicly available online. ${ }^{31}$

\section{KEY FINDINGS FROM ANALYSIS OF INSPECT SYSTEM DATA}

\section{A. Trends in Opioid Dispensations}

INSPECT data offer a valuable resource for tracking trends in the dispensation of controlled substances, which is of particular importance for opioid analgesics due to their high rates of misuse and abuse, significant potential for dependence, and clear link to fatal overdoses. ${ }^{32}$ Using the INSPECT data provided to us by IPLA for our evaluation ${ }^{33}$, we found that since 2010, pharmacists have dispensed, on average, 13,338,496 controlled substances per year, with prescription opioid medication accounting for an average of $48.0 \%$ of dispensations. In 2015, pharmacies made 13,216,732 dispensations of controlled substances with 48.9\% $(6,458,471$ dispensations) for opioids. Opioid dispensations peaked in 2012 at 6,728,298 dispensations and dropped by $7.0 \%$ to their lowest point in 2014, but have increased somewhat in 2015. While there has been some variation over the past six years, the overall trend has been toward fewer opioid dispensations, as illustrated by Figure 1 below.

${ }^{29}$ INSPECT, Indiana's Prescription Drug Monitoring Program, http://www.healthlinc.org/ [https://perma.cc/SY6D-9EJ3] (last visited Jan. 10, 2017).

${ }^{30}$ About INSPECT, supra note 20.

31 See Harold Kooreman et al., Key Findings and Recommendations from the 2013 IPLA INSPECT Knowledge and Use survey, (June 2014); See also Harold Kooreman et al., The Indiana INSPECT Evaluation: Key Findings and Recommendations from a Descriptive Analysis of INSPECT Data, (Sept. 2014).

32 Manchikanti \& Singh, supra note 8; Paulozzi et al. supra note 15.

33 Indiana Professional Licensing Agency. (2016). Indiana INSPECT Data Set-2014. Information received, Feb. 11, 2016, from Amanda Garrett, Director of Operations, INSPECT. 


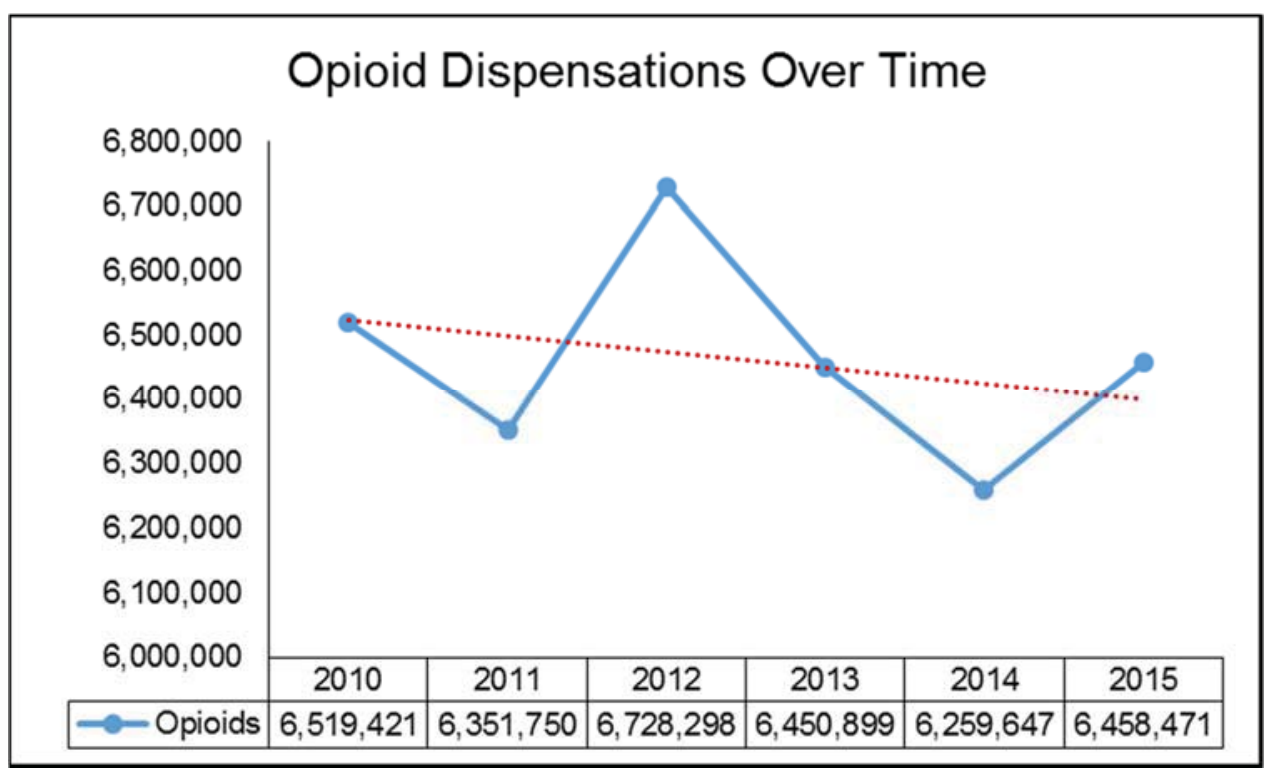

Figure 1. Trends in Opioid Dispensations in Indiana, 2010-2015 ${ }^{34}$

Table 1 displays the eight most frequently dispensed opioids in Indiana for 2014 found in the INSPECT data system. The most commonly dispensed opioid analgesic in Indiana during 2014 was Hydrocodone Bitartrate/Acetaminophen (i.e., Vicodin ${ }^{\circledR}$ ), accounting for $59.0 \%$ of opioid dispensations. Oxycodone Hydrochloride/Acetaminophen (i.e., Percocet ${ }^{\mathbb{R}}$ ) was the second most commonly dispensed opioid with $10.7 \%$ of opioid dispensations. Hydrocodone Bitartrate/Acetaminophen and Oxycodone Hydrochloride/Acetaminophen have been the most frequently dispensed opioids since at least 2010. Individuals to whom opioids were dispensed were more likely to be female, older, and living in more urban areas (see Table 2).

\begin{tabular}{|l|c|c|}
\hline Opioid & \# of Dispensations & $\begin{array}{c}\% \text { of Opioid } \\
\text { Dispensations }\end{array}$ \\
\hline $\begin{array}{l}\text { Hydrocodone Bitartrate/ } \\
\text { Acetaminophen }\end{array}$ & $3,690,478$ & 59.0 \\
\hline $\begin{array}{l}\text { Oxycodone Hydrochloride/ } \\
\text { Acetaminophen }\end{array}$ & 666,974 & 10.7 \\
\hline Tramadol Hydrochloride & 395,820 & 6.3 \\
\hline Oxycodone Hydrochloride & 334,375 & 5.3 \\
\hline Morphine Sulfate & 249,250 & 4.0 \\
\hline Buprenorphine/Naloxone & 234,192 & 3.7 \\
\hline Acetaminophen/Codeine Phosphate & 188,500 & 3.0 \\
\hline Fentanyl & 148,239 & 2.4 \\
\hline
\end{tabular}

Table 1. Frequency of Most Commonly Dispensed Opioids 35

\footnotetext{
${ }^{34} \mathrm{Id}$. at 33 (the dotted line indicates a computed trend line based on the actual data).

${ }^{35} I d$.
} 


\begin{tabular}{|c|c|c|c|c|}
\hline Demographic & $\begin{array}{l}\text { Number who } \\
\text { Received an } \\
\text { Opioid }\end{array}$ & $(\%)$ & $x^{2}$ & $\mathbf{P}$ \\
\hline Gender & & & 203.8 & $<.001$ \\
\hline Male & 657,940 & $(43.0)$ & & \\
\hline Female & 873,108 & $(57.0)$ & & \\
\hline Age Category & & & 60103.5 & $<.001$ \\
\hline 0-9 & 16,523 & $(1.1)$ & & \\
\hline 10-19 & 88,319 & $(5.8)$ & & \\
\hline 20-29 & 205,181 & (13.4) & & \\
\hline 30-39 & 235,486 & (15.4) & & \\
\hline $40-49$ & 240,923 & $(15.7)$ & & \\
\hline $50-59$ & 292,534 & (19.1) & & \\
\hline $60-69$ & 229,240 & $(15.0)$ & & \\
\hline 70 and Older & 223,530 & (14.6) & & \\
\hline Metro/Non-Metro & & & 905.9 & $<.001$ \\
\hline Metro Area & $1,114,669$ & $(75.9)$ & & \\
\hline Non-Metro Area & 354,858 & $(24.1)$ & & \\
\hline
\end{tabular}

Table 2. Opioid Dispensations by Demographic Characteristics ${ }^{36}$

\section{B. Doctor-Shopping}

Individuals who misuse opioid analgesics often acquire their prescriptions through the practice of doctor-shopping and then may fill these prescriptions at various different pharmacies as a way to avoid detection (i.e., pharmacy-shopping). The data contained in INSPECT can be useful for identifying persons who appear to be engaging in doctor-shopping. Currently, no universally accepted definition exists for doctor-shopping. In 2010 the Indiana State Board of Pharmacy ("ISBP") defined INSPECT's threshold for considering someone to be a doctor-shopper if he or she, "received controlled substances prescriptions from 10 or more unique prescribers in a continuous 60-day period." "37 A second definition developed by The Bureau of Justice Assistance ("BJA") outlines a doctor-shopper as someone who obtains, "controlled substance prescriptions from at least [five] unique prescribers and fills these prescriptions at [five] unique pharmacies in a [three]-month period." 38

Using these two definitions for doctor-shopping, we analyzed 2014 INSPECT data for individuals who received opioids were analyzed to determine the number and demographic characteristics of doctor-shoppers in the State. ${ }^{39}$ During 2014, most patients who received opioid

${ }^{36} \mathrm{Id}$.

37 ERIC R. Wright et AL., The Indiana INSPECT Evaluation: Key Findings AND RECOMMENDATIONS FROM A DESCRIPTIVE ANALYSIS OF INSPECT DATA 2014 (2014), https://www.healthpolicy.iupui.edu/ [https://perma.cc/M7RB-WNU4].

${ }^{38}$ Id. at 38 .

39 Indiana Professional Licensing Agency. (2016). Indiana INSPECT Data Set-2014. Information received, Feb. 11, 2016, from Amanda Garrett, Director of Operations, INSPECT. 
medication visited one or a small number of prescribers. ${ }^{40}$ The average number of prescribers was $2.54(\mathrm{SD}=2.40$; median $=1.00)$; however, the range of providers visited was from one to 58 . Patients filled their prescriptions at 2.05 pharmacies on average $(\mathrm{SD}=1.76$; median $=1.00)$ with a range of one to 33 pharmacies. ${ }^{41}$

The number of doctor-shoppers identified varied significantly depending upon the definition used. When the ISBP doctor-shopper definition was used, patients selected were ones who had received opioid prescriptions from 10 or more prescribers within a continuous 60-day period which was defined by the date of their first opioid dispensation. A total of 73 unique patients were identified for 2014 that met the ISBP criteria for doctor-shopping. ${ }^{42}$ Doctor-shoppers ranged in age from 22 to 72 , with a mean age of 40.9 years $(\mathrm{SD}=11.86){ }^{43}$ Thirty-eight $(52.1 \%)$ doctorshoppers were female and $35(47.9 \%)$ were male. ${ }^{44}$ When the more liberal BJA definition for doctor-shopping was used, a total of 1,153 patients in 2014 met the doctor-shopper criteria. ${ }^{45}$ BJA doctor-shoppers were more likely to be female $(55.3 \%)$ than male $(44.7 \%)$ and ranged in age from 13 to 93 with a mean age of $40.12(\mathrm{SD}=12.79) .{ }^{46}$ In 2014,60 patients met the doctor-shopper criteria under both the ISBP and BJA definitions. ${ }^{47}$ These 60 individuals were split equally between men and women with ages ranging from 22 to $72\left(\mathrm{M}=42.23\right.$; SD = 12.60). ${ }^{48}$ Table 3 provides a comparison between individuals who were and were not doctor-shoppers using both definitions of doctor-shopping.

\begin{tabular}{|l|c|c|c|c|c|}
\hline & \multicolumn{2}{c}{$\begin{array}{c}\text { ISBP Doctor } \\
\text { Shoppers }\end{array}$} & \multicolumn{2}{c|}{$\begin{array}{c}\text { Shoppers } \\
\text { Shon-Doctor- }\end{array}$} \\
\hline & Mean & Median & Mean & Median & P \\
\hline Age & 40.90 & 40.00 & 48.12 & 49.00 & $<.0001$ \\
\hline $\begin{array}{l}\text { Total \# of Opioid } \\
\text { Prescriptions }\end{array}$ & 33.75 & 30.00 & 4.14 & 2.00 & $<.0001$ \\
\hline & & & & & \\
\hline & BJA Doctor & BJA Non-Doctor- & \\
\hline & Shoppers & Shoppers & Median & P \\
\hline Age & Mean & Median & Mean & Median \\
\hline Total \# of Opioid Prescriptions & 21.40 & 19.00 & 4.13 & 2.00 & $<.0001$ \\
\hline
\end{tabular}

Table 3. Comparisons between Individuals who were and were not Doctor-Shoppers in $2014^{49}$

\footnotetext{
${ }^{40}$ WRIGHT, supra note 37.

${ }^{41} \mathrm{Id}$.

${ }^{42} I d$.

${ }^{43} \mathrm{Id}$.

${ }^{44}$ Id.

${ }^{45}$ Id.

${ }^{46} \mathrm{Id}$.

${ }^{47} \mathrm{Id}$.

${ }^{48} \mathrm{Id}$.

${ }^{49}$ Id. at 39.
} 


\section{KEY FINDINGS From the 2013 SURVEY of PRESCRIBERS’ AND DisPENSERS’ USE OF INSPECT}

PDMPs can be important tools in tackling the widespread misuse and abuse of prescription drugs by reducing diversion of controlled substances and improving clinical decision-making through increased access to detailed patient prescription histories. ${ }^{50}$ For PDMPs to be effective in deterring prescription drug abuse, healthcare providers need to actually use them. ${ }^{51}$ In an initial attempt to understand Indiana's healthcare professionals' experience with INSPECT, the IUPUI Center for Health Policy ("CHP"), in collaboration with the IPLA and the State Prescription Drug Abuse Prevention Task Force's Education Committee, developed the IPLA INSPECT Knowledge and Use Survey. ${ }^{52}$ The web-based survey asked prescribers' and dispensers' of controlled substances about their knowledge, use, and opinions of INSPECT as well as their attitudes and beliefs about prescribing and dispensing opioids. The survey was distributed electronically to all Indiana licensed prescribers and dispensers. IPLA staff identified 38,333 potential respondents that met the survey's inclusion criteria and invited them to participate. ${ }^{53}$ A total of 5,994 completed the survey for a response rate of $15.6 \%{ }^{54}$ The type of license held by $106(1.8 \%)$ of the respondents could not be determined. ${ }^{55}$ Of the 5,888 survey respondents who provided licensure information, Medical doctors and pharmacists accounted for the majority (37.4\% and $26.9 \%$ respectively; see Table 4). ${ }^{56}$

\begin{tabular}{|l|r|r|}
\hline Licensure Type & $\begin{array}{l}\text { Number who Completed } \\
\text { Survey }\end{array}$ & $\begin{array}{c}\text { \% } \\
\text { Survey Completed }\end{array}$ \\
\hline Medical Doctor (MD) & 2,204 & 37.4 \\
\hline Pharmacist (Pharm D or Pharm BS) & 1,582 & 26.9 \\
\hline Nurse Practitioner (NP) & 886 & 15.0 \\
\hline Dentist (DDS or DMD) & 753 & 12.8 \\
\hline Doctor of Osteopathy (DO) & 191 & 3.2 \\
\hline Physician Assistant (PA) & 181 & 3.1 \\
\hline Doctor of Podiatric Medicine (DPM) & 49 & 0.8 \\
\hline Other License Type & 42 & 0.7 \\
\hline Total with licensure information & 5,888 & \\
\hline
\end{tabular}

Table 4. Composition of INSPECT Survey Sample 57

${ }^{50}$ PDMP CTR. OF EXCELLENCE, BRANDEIS UNIV., BRIEFING ON PDMP EFFECTIVENESS, 1, 3, (2014), http://www.pdmpassist.org/ [https://perma.cc/3FNP-WT4D].

${ }^{51} I d$. at 4.

${ }^{52}$ For a general summary of the survey methodology and key findings, see ERIC R. WRIGHT ET AL., KEY FindingS AND RECOMMENDATIONS FROM THE 2013 IPLA INSPECT KNOWLEDGE AND USE SURVEY 4 (2014), http://www.healthpolicy.iupui.edu [https://perma.cc/LP3D-SAF6].

${ }^{53} \mathrm{Id}$. at 43.

${ }^{54} \mathrm{Id}$.

${ }^{55} \mathrm{Id}$.

${ }^{56} \mathrm{Id}$.

${ }^{57} \mathrm{Id}$. 
Results of the survey indicated that most $(85.0 \%)$ respondents had heard of INSPECT. ${ }^{58}$ Pharmacists $(94.3 \%)$ were more likely than other groups to know about the database. ${ }^{59}$ For this paper, we completed a logistic regression analysis to predict a respondent's awareness of INSPECT based on his or her license type. The results indicated that compared to pharmacists, DPMs were 6.2 times, MDs were 5.0 times, DOs and Dentists were 4.0 times, and unspecified professionals were 3.0 times less likely to know about INSPECT. ${ }^{60}$

\begin{tabular}{|c|c|c|c|c|}
\hline Licensure Type & Knew About Inspect & $(\%)$ & O.R. & $\mathbf{P}$ \\
\hline Medical Doctor & 1,660 & 76.9 & .20 & $<.001$ \\
\hline Doctor of Osteopathy & 151 & 80.3 & .24 & $<.001$ \\
\hline Doctor of Podiatric Medicine & 35 & 72.9 & .16 & $<.001$ \\
\hline Physician Assistant & 167 & 93.3 & .83 & .57 \\
\hline Nurse Practitioner & 810 & 92.4 & .72 & .06 \\
\hline Dentist & 598 & 80.7 & .25 & $<.001$ \\
\hline Other & 34 & 85.0 & .34 & .02 \\
\hline Pharmacist & 1,469 & 94.3 & -- & -- \\
\hline
\end{tabular}

Table 5. Knowledge of INSPECT ${ }^{61}$ 
While awareness of INSPECT was relatively high among the respondents, overall, only 70.7\% of those who knew about INSPECT used it. ${ }^{62}$ Among specific professions, more DOs reported use of INSPECT (89.2\%). ${ }^{63}$ Logistic regression analyses of respondents' reported use of INSPECT suggested that, compared with DOs, Dentists were 8.3 times, DPMs were 7.7 times, MDs were 3.3 times, Pharmacists and unspecified professionals were 3.2 times, NPs were 2.3 times, and PAs were 2.0 times less likely to have used INSPECT (see Table 6).

\begin{tabular}{|c|c|c|c|c|}
\hline Licensure Type & $\begin{array}{l}\text { Had used } \\
\text { INSPECT }\end{array}$ & $(\%)$ & O.R. & $\mathbf{P}$ \\
\hline Medical Doctor & 1,148 & $(71.0)$ & .30 & $<.001$ \\
\hline Doctor of Osteopathy & 132 & $(89.2)$ & -- & -- \\
\hline Doctor of Podiatric Medicine & 17 & $(51.5)$ & .13 & $<.001$ \\
\hline Physician Assistant & 134 & $(80.7)$ & .51 & .04 \\
\hline Nurse Practitioner & 623 & $(78.3)$ & .44 & .003 \\
\hline Dentist & 292 & $(50.4)$ & .12 & $<.001$ \\
\hline Pharmacist & 1,043 & $(71.8)$ & .31 & $<.001$ \\
\hline Other & 24 & $(72.7)$ & .32 & .02 \\
\hline
\end{tabular}

Table 6. Use of INSPECT by Professionals Who Knew of INSPECT ${ }^{64}$

As noted earlier, many individuals who misuse and abuse prescription pharmaceuticals obtain their medications from multiple providers. Prescribers can curtail this behavior by regularly monitoring their patients' INSPECT information. ${ }^{65}$ Data gathered from controlled substance prescribers ("CSPs") who completed the INSPECT survey may help answer questions about INSPECT use and prescribing behaviors. We used these survey data to answer three research questions: 1) what factors are associated with a CSP's use of INSPECT; 2) what factors are associated with the frequency of a CSP's INSPECT use; and 3) what factors are associated with a CSP changing his or her prescribing behavior? The three primary outcome measures used to answer the questions of interest are use of INSPECT, frequency of INSPECT use, and self-reported change in a CSP's prescribing behavior in the past 12 months. Relevant demographic, practice, and patient and community belief variables served as independent predictors in each analysis. The analysis sample was composed of four CSP groups: MDs, DOs, NPs and PAs combined, and Dentists. Due to the small number of DPMs, they were excluded from the sample.

\footnotetext{
${ }^{62} I d$.

${ }^{63} \mathrm{Id}$.

${ }^{64} \mathrm{Id}$

${ }^{65}$ See id. at 16.
} 


\begin{tabular}{|c|c|c|}
\hline \multicolumn{3}{|c|}{ Variables in Analyses } \\
\hline Outcome Variables & Coding Scheme & $\begin{array}{l}\text { Reference } \\
\text { Category }\end{array}$ \\
\hline Any Use of INSPECT & $1=$ Use, $0=$ No Use & $\mathrm{n} / \mathrm{a}$ \\
\hline Frequency of INSPECT Use & $\begin{array}{l}0=\text { Never } \\
1=\text { Periodically } \\
2=\text { At Every Visit }\end{array}$ & Never \\
\hline $\begin{array}{l}\text { Change in Prescribing Behavior in Past } 12 \\
\text { Months }\end{array}$ & $1=$ Change, $0=$ No Change & $\mathrm{n} / \mathrm{a}$ \\
\hline \multicolumn{3}{|l|}{ Predictor Variables } \\
\hline Gender & $1=$ Female, $0=$ Male & Male \\
\hline Race & $1=$ Nonwhite, $0=$ White & White \\
\hline Type of Practice & $\begin{array}{l}1=\text { Pediatric, } 0=\text { Non- } \\
\text { pediatric }\end{array}$ & $\begin{array}{l}\text { Non- } \\
\text { pediatric }\end{array}$ \\
\hline Practice Setting & $1=$ Outpatient $0=$ Inpatient & Inpatient \\
\hline License & $\begin{array}{l}1=\mathrm{MD}, 2=\mathrm{DO}, 3= \\
\mathrm{NP} / \mathrm{PA} \\
4=\text { Dentist }\end{array}$ & $\mathrm{MD}$ \\
\hline Years in Practice & $\mathrm{n} / \mathrm{a}$ & $\mathrm{n} / \mathrm{a}$ \\
\hline Rural/Urban Classification & $\begin{array}{l}\text { USDA Economic Research } \\
\text { Service Rural Urban } \\
\text { Continuum Codes }\end{array}$ & $\mathrm{n} / \mathrm{a}$ \\
\hline$\%$ of Patients in Practice on Opioids & $\mathrm{n} / \mathrm{a}$ & $\mathrm{n} / \mathrm{a}$ \\
\hline$\%$ of Patients in Practice on Stimulants & $\mathrm{n} / \mathrm{a}$ & $\mathrm{n} / \mathrm{a}$ \\
\hline \% of Patients in Practice on Depressants & $\mathrm{n} / \mathrm{a}$ & $\mathrm{n} / \mathrm{a}$ \\
\hline $\begin{array}{l}\text { \% of Patients in Practice Being Treated for } \\
\text { Chronic Pain }\end{array}$ & $\mathrm{n} / \mathrm{a}$ & $\mathrm{n} / \mathrm{a}$ \\
\hline $\begin{array}{l}\text { Concern About Prescription Medication } \\
\text { Abuse in Community }\end{array}$ & $\begin{array}{l}0=\text { not concerned at all, } \\
1=\text { slightly concerned, } \\
2=\text { moderately concerned, } \\
3=\text { extremely concerned }\end{array}$ & $\mathrm{n} / \mathrm{a}$ \\
\hline $\begin{array}{l}\text { Concern About Prescription Medication } \\
\text { Abuse in Own Practice }\end{array}$ & $\begin{array}{l}0=\text { not concerned at all } \\
1=\text { slightly concerned } \\
2=\text { moderately concerned } \\
3=\text { extremely concerned }\end{array}$ & $\mathrm{n} / \mathrm{a}$ \\
\hline $\begin{array}{l}\text { Number of Barriers Encountered for Using } \\
\text { INSPECT }\end{array}$ & $\mathrm{n} / \mathrm{a}$ & $\mathrm{n} / \mathrm{a}$ \\
\hline
\end{tabular}

Table 7. Description of Outcome and Predictor Variables Used in Analyses. ${ }^{66}$

To address the questions regarding INSPECT use and CSPs' change in prescribing behavior, binomial and multinomial logistic regression with backward elimination were used to fit the models and to include all conceptually relevant independent variables to reduce the possibility of a suppressor effect within the models.

${ }^{66}$ ERIC R. WRIGHT ET AL., IPLA INSPECT Knowledge and Use Survey Data Set—2013. 


\section{A. Factors Associated with INSPECT Use}

The final binomial model predicting any INSPECT use retained one demographic, two practice, and three belief variables. Use of INSPECT was predicted by fewer years in practice; having a non-pediatric practice, working in an outpatient setting, having fewer barriers in one's practice to using INSPECT, believing a larger percentage of patients in one's practice was on stimulants, having more patients in one's practice with chronic pain, and having greater concern about prescription medication abuse among one's patients. License type was also significantly associated with using the INSPECT system. Compared to MDs, Dentists were 2.2 times less likely to use INSPECT.

\begin{tabular}{|c|c|c|c|}
\hline Predictor & & $\mathbf{O . R .}$ & $\mathbf{P}$ \\
\hline Years in Practice & -0.031 & .970 & $<.001$ \\
\hline Pediatric Practice & -1.349 & .259 & $<.001$ \\
\hline Outpatient Setting & 1.457 & 4.295 & $<.001$ \\
\hline License Type & & & $<.001$ \\
\hline D.O. & .754 & 3.781 & .052 \\
\hline $\mathbf{N P} / \mathbf{P A}$ & -.124 & .833 & .361 \\
\hline Dentist & -.912 & .402 & $<.001$ \\
\hline Barriers to INSPECT Use & -.393 & .675 & $<.001$ \\
\hline Percent of Patients on Stimulants & .150 & 1.162 & $<.001$ \\
\hline Percent of Patients with Chronic Pain & .102 & 1.108 & $<.001$ \\
\hline $\begin{array}{l}\text { Concern Regarding Patients who Misuse } \\
\text { Medications }\end{array}$ & .662 & 1.940 & $<.001$ \\
\hline \multicolumn{4}{|c|}{ Chi Sq. $=587.222, p<.001 ;$ Nagelkerke $R$ Sq. $=.303$} \\
\hline
\end{tabular}

Table 8. Binary Logistic Regression Predicting Any Use of INSPECT ${ }^{67}$

\section{B. Frequency of INSPECT Use}

Because frequency of INSPECT use was coded into three categories, the authors used multinomial regression to compare CSPs who periodically or always used INSPECT to those who

${ }^{67} \mathrm{Id}$. 
never used INSPECT. The results suggest that when compared to CSPs who never used INSPECT, periodic use was predicted by having a non-pediatric practice, by having fewer barriers in one's practice associated with using INSPECT, and by expressing greater concern about controlled substance medication misuse or abuse among one's patients. Compared to MDs, dentists were less likely to report using INSPECT on a periodic basis. When CSPs who checked INSPECT on every visit were compared to those who never checked INSPECT, they were more likely to have a nonpediatric practice, less likely to be in an inpatient setting, have a larger percentage of patients with chronic pain in their practice, have been practicing for a shorter period, have fewer barriers in their practice tied to checking INSPECT, and express greater concern regarding prescription medication abuse by their patients. Dentists, when compared to MDs, were less likely to report always using INSPECT when meeting with patients on controlled substances.

\begin{tabular}{|c|c|c|c|}
\hline \multicolumn{4}{|c|}{ Periodically Checks INSPECT } \\
\hline Predictor & $\mathrm{B}$ & O.R. & $\mathrm{P}$ \\
\hline Years in Practice & -0.018 & 0.982 & 0.134 \\
\hline Non-Pediatric Practice & 1.834 & 6.257 & $<.001$ \\
\hline Inpatient Setting & 0.210 & 1.233 & 0.709 \\
\hline \multicolumn{4}{|l|}{ License } \\
\hline DO & 0.895 & 2.448 & 0.387 \\
\hline NP/PA & 0.376 & 1.456 & 0.333 \\
\hline Dentist & -0.748 & 0.473 & 0.047 \\
\hline Barriers to INSPECT Use & -0.473 & 0.623 & 0.002 \\
\hline Percent of Patients with Chronic Pain & 0.439 & 1.551 & 0.053 \\
\hline $\begin{array}{l}\text { Concern Regarding Patients who Misuse } \\
\text { Medication }\end{array}$ & 0.550 & 1.733 & 0.003 \\
\hline $\begin{array}{l}\text { Concern Regarding Community Misuse of } \\
\text { Medication }\end{array}$ & -0.130 & 0.878 & 0.518 \\
\hline \multicolumn{4}{|c|}{$\begin{array}{l}\text { Always Checks INSPECT } \\
\end{array}$} \\
\hline & B & O.R. & $\mathrm{P}$ \\
\hline Years in Practice & -0.038 & 0.963 & 0.011 \\
\hline Non-Pediatric Practice & 3.020 & 20.495 & 0.006 \\
\hline Inpatient Setting & -1.664 & 0.189 & 0.041 \\
\hline \multicolumn{4}{|l|}{ License } \\
\hline DO & 0.873 & 2.393 & 0.423 \\
\hline NP/PA & 0.639 & 1.894 & 0.135 \\
\hline Dentist & -1.582 & 0.205 & 0.009 \\
\hline Percent of Patients with Chronic Pain & 0.657 & 1.929 & 0.010 \\
\hline Barriers to INSPECT Use & -0.888 & 0.411 & 0.000 \\
\hline $\begin{array}{l}\text { Concern Regarding Patients who Misuse } \\
\text { Medication }\end{array}$ & 0.874 & 2.396 & 0.000 \\
\hline $\begin{array}{l}\text { Concern Regarding Community Misuse of } \\
\text { Medication }\end{array}$ & 0.377 & 1.458 & 0.148 \\
\hline
\end{tabular}

Chi Sq. = 199.139, $p<.001 ;$ Nagelkerke $R$ Sq. $=.181$ 
Table 9. Predictors of Frequency of INSPECT Use 68

\section{Change in Prescribing Practices in the Past Twelve Months}

The final binomial regression model predicting self-reported change in prescribing behavior in the past twelve months contained one demographic, two practice, and three belief variables. CSPs, who changed their prescribing behavior were more likely to: 1) be female, 2)-have a non-pediatric practice, 3) report checking INSPECT at least periodically for their patients on controlled substances, 4) believe more patients in their practice were on stimulant medication, 5) have a higher percentage of patients in their practice with chronic pain, and 6) endorse greater concern about prescription drug misuse and abuse by their patients. Occupation was also associated with change in prescribing behavior. Dentists were less likely to report having changed their prescribing behavior in the past twelve months compared to MDs. (see Table 10).

\begin{tabular}{|c|c|c|c|}
\hline & B & O.R. & $\mathbf{P}$ \\
\hline Gender & 0.284 & 1.329 & 0.031 \\
\hline Years in Practice & 0.009 & 1.009 & 0.083 \\
\hline Pediatric Setting & -0.993 & 0.371 & 0.006 \\
\hline \multicolumn{4}{|l|}{ License } \\
\hline DO & -0.236 & 0.790 & 0.301 \\
\hline NP/PA & 0.133 & 1.142 & 0.345 \\
\hline Dentist & -0.454 & 0.635 & 0.027 \\
\hline $\begin{array}{l}\text { INSPECT Use (Periodically or Always versus } \\
\text { Never) }\end{array}$ & 0.799 & 2.223 & 0.021 \\
\hline Percent of Patients on Stimulant Medication & 0.183 & 1.200 & 0.000 \\
\hline Percent of Patients with Chronic Pain & 0.465 & 1.592 & 0.000 \\
\hline $\begin{array}{l}\text { Concern Regarding Patients who Misuse } \\
\text { Medication }\end{array}$ & 0.240 & 1.271 & 0.000 \\
\hline
\end{tabular}

Chi Sq. = 179.431, $p$ <.001; Nagelkerke $R$ Sq = .141

Table 10. Predictors of Change in Prescribing Behavior ${ }^{69}$

\section{CONCLUSION}

Like many states in the nation, Indiana is struggling to address the problem of nonmedical use of prescription medications, particularly prescription opioid analgesics. PDMPs are one method that has proven successful in reducing access to opioids to individuals who acquire them through multiple prescriptions and pharmacies. ${ }^{70}$ INSPECT is helping healthcare practitioners address nonmedical use of controlled substance medication by identifying individuals who have suspicious

${ }^{68} I d$.

${ }^{69} \mathrm{Id}$. at 52.

${ }^{70}$ Julie Worley, Prescription Drug Monitoring Programs, A Response to Doctor-Shopping: Purpose, Effectiveness, and Directions for Future Research, 33 Issues IN MENTAL HeAlth NuRSING Issues 319, 319-28 (2012). 
prescription activity. Depending on how suspicious activity is defined, we estimate that Indiana may have anywhere from 73 to 1,153 Hoosiers engaging in doctor-shopping to obtain opioid analgesics. It is essential for healthcare providers to identify doctor-shoppers, not only to reduce potential diversion of prescription opioids, but also to encourage these individuals to seek treatment and lessen their risk for fatal overdose.

To identify doctor-shoppers in one's practice, prescribers need to regularly check INSPECT for the names of their patients on opioids and other controlled substances. Unfortunately, in Indiana, only $70.7 \%$ of healthcare providers, who were familiar with INSPECT, used it. And, among those who did use it, the majority only did so only on a periodic basis. INSPECT use was clearly related to a provider's practice with dentists and podiatrists being significantly less likely to use it with any of their patients as were pediatricians and prescribers working in inpatient settings. Healthcare providers, who used INSPECT regularly, were younger, had more chronic pain patients in their practice, reported a greater level of concern regarding their patients' nonmedical use of controlled prescription medication, and perceived fewer barriers to using INSPECT within their practice.

Apart from helping reduce doctor-shopping, INSPECT appears to have played a role in getting some prescribers to change their prescribing habits, typically in the direction of prescribing fewer controlled substances. Female prescribers, those not working in pediatric settings, those more sensitive to issues of nonmedical use, and those who provide care to more patients in chronic pain, were more likely to report having changed their prescription practices in the twelve months prior to the survey. INSPECT use was also related to shifts in prescribing with prescribers who used INSPECT, at least periodically, being more likely to change their prescribing behavior than those who never used it.

Results from these analyses appear to suggest that INSPECT is influencing the overall supply of controlled prescription medication entering Indiana communities. To enhance INSPECT'S effectiveness, additional efforts need to be made to raise awareness about nonmedical use of controlled medication particularly among prescribers who may not often treat patients with chronic pain. Outreach and additional training for older prescribers, who may be uncomfortable using electronic databases, and providers, who perceive significant barriers to using INSPECT, could also serve to increase the frequency with which they consult it. 